Explorar o poder de referência da linguagem é trabalhar no limite mesmo onde a realidade extratextual surge como uma visão, dentro do texto, reconhecível (há o desejo de compartilhar uma percepção sobre a realidade, de propor uma perspectiva coletiva) e, simultaneamente, irreconhecivel (há o desejo de se deslocar a percepção automatizada e massificada da realidade). Entre narrativa e leitor, busca-se, ao mesmo tempo, a convergência e a divergência de olhares. O Brasil delineado é, desse modo, um Brasil verdadeiro e absurdo, banal e estranhíssimo, sensato e alucinado, óbvio e surpreendente. Entre texto e realidade, identificação e desencaixe: dentro e fora.

Crível e incrível.

\section{VIVIRSE EN LA LITERATURA: LOS NARRADORES EN LAS NOVELAS DE HAROLDO CONTI}

Graciela Ravetti $U F M G$

\author{
RESUMO
}

O presente trabalho faz parte de uma pesquisa que toma como objeto os quatro romances de Haroldo Conti, escritor argentino contemporâneo, com o objetivo de construir um modelo das estruturas literárias em relação com o imaginário do texto; construção que permita uma leitura dos imaginários sociais de toda uma comunidade. É assim que abordamos os modos de representação literária dos narradores como um dos modos de naturalizar as convenções .
REVISTA DE ESTUDOS DE LITERATURA Belo Horizonte, v. 3, p. 83 - 101, out. 95

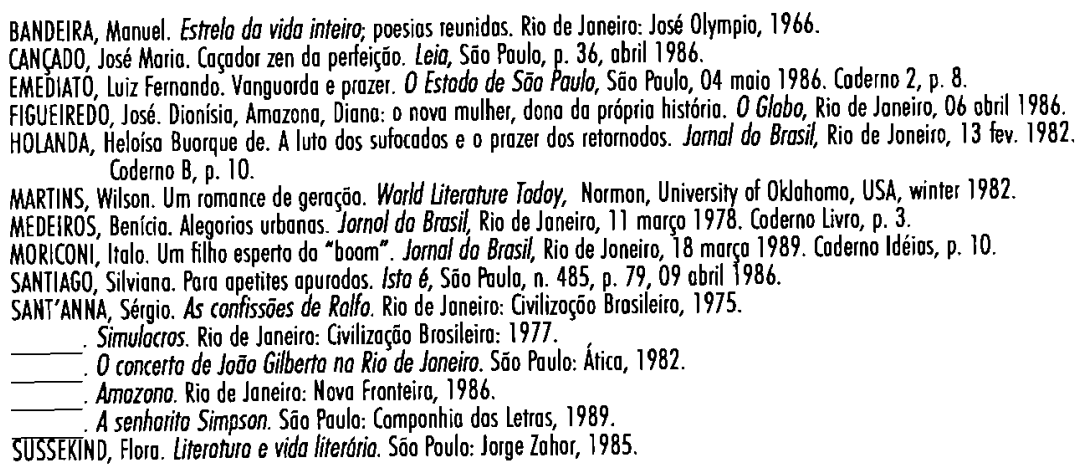


Por supuesto quisiera ser un escritor comprometido en su totalidad. Que mi obra fuese un firme puño, un claro fusil. Pero decididamente no lo es. Es que mi obra me toma relativamente en cuenta, se hace un poco a mi pesar, se me escapa de las manos, casi diría que se escribe sola y llegado el caso lo único que siento como una verdadera obligación es hacer las cosas cada vez mejor, que mi obra, nuestra obra, como dice Galeano, tenga más belleza que la de los otros, los enemigos.

Haroldo Conti

El narrador en las novelas de Haroldo Conti es un tipo de conocedor de aquellos de los que habla Walter Benjamin': sabe tanto dar consejos como expresar opiniones a partir de la sustancia viva de la experiencia. Son narradores capaces de ejercitar el arte de contar historias, de intercambiar experiencias, justamente como el autor, que fue un hombre que conjugó una manera de vivir con una manera de escribir y una manera de morir.

A esta altura de las cosas la literatura se me aparece como un destino (no un fin en sí mismo), mi particular manera de vivir y consistir. Por lo menos he tratado de que sea así, buscando juntar la vida y la literatura, hacer una sola cosa. No aquí la vida y allí la literatura. Tal vez en ese sentido el viejo Hemingway dijo que el talento reside en cómo uno vive la vida (...)

Por supuesto, como vida, esto es, como totalidad, no se reduce al solitario hecho de escribir sino a una actitud general, una especie de revelación, por mi lado, y por el otro, el del lector y aun el del mero espectador, a un tipo de participación que curiosamente me lleva a un despojamiento cada vez mayor de lo personal (...) para que los demás asuman mis historias, como actos más que como relatos, cual si fueran propias, las participen, que es algo más que leer, y las incorporen a sus vidas. Asi a través de mis personajes soy yo el que me vivo. Me vivo en historias que fueron o pudieron ser, no importa su correspondencia efectiva en el tiempo porque después de todo el tiempo sin nosotros es nada. Y todo lo que pretendo, porque queda por ver si efectivamente lo he logrado, es que otros, la mayoría de los

1. BENJAMIN, 1987.p. 197-221.

2. Haroldo Conti fue secuestrado por tuerzas parapolicioles. Desaparecido, fue dodo por muerto en 1976 en Buenos Aires. Testigos detalloron horrendas torturos a las que Conti fue sometido. cuales no llegaré a conocer, se vivan a partir de esa minúscula sucesión de signos que mientras alguien no los anima, apenas son un trazo de tinta.

De una vida llena de experiencias y de aventuras, muchas de ellas narradas en sus novelas, sus narraciones se acercan mucho a las historias orales a través de las cuales viajeros y sedentarios transmiten saber. La operación de recuperar textos orales populares implica que, en el momento de la transcripción, se lleve al texto escrito el contexto de origen. "Se ligan así dos formas verbales, la 'oral' y la escrita. En esas zonas se distribuyen los tonos, enunciados, nombres, fuerzas, se asignan funciones y jerarquías". El marco de la voz oral se ubica en el diálogo: los hombres que traen esta voz son identificados en su contexto específico, que establece fronteras entre el espacio de lo público y de lo privado, zonas cuya conjunción o separación son marcas de cambio en la historia literaria. Las experiencias personales de Conti en sus viajes, cortos y largos, vía río, mar o tierra, le proveían elementos de investigación literaria que pueden ser evaluados en toda su obra por las huellas que dejan en su prosa de ficción y que permiten la observación del proceso de transposición literaria de lo 'real' a la literatura. De dos familias de narradores nos habla Benjamin y ambas aparecen en la narrativa contiana: los que andan por el mundo y tienen el saber de las tierras distantes y los sedentarios que poseen el saber del pasado. Su entrecruzamiento define ópticas y objetivos modificadas a lo largo del tiempo, tal como ocurrió con las perspectivas de vida y militancia del autor, las relaciones de producción y los modos de conformación de la sociedad y por ende, con los imaginarios sociales, constructores privilegiados de lo social y sobre los cuales la narrativa se diseña.

Haroldo Conti nació en Chacabuco, un pueblo del interior de Buenos Aires. Fue seminarista, camionero, profesor de latín. Le gustaba viajar; adoraba el Delta, el Tigre, los viajes por mar recorriendo las costas poco exploradas del litoral argentino, uruguayo y brasileño. De cada lugar, le interesaba la gente y sus modos de sobrevivencia: cómo vivían, cómo se divertían, cómo trabajaban. Hacía amigos entre los isleños y siempre volvía para compartir experiencias, conversar con ellos. Así fue conociendo todo tipo de personas especiales, 'raras', 'distintas' que dieron base a la

3. Froggmento del "Discurso en Coso de las Américas", en La Habana, Cubo, porticipando como jurado del concurso literario. In: RESTIYO, SANCHEL, 1986. p. 169 .

4. LUDMER, 1988. p. 71 
construcción de los personajes de sus cuentos, novelas y trabajos periodísticos.

Benjamin ${ }^{5}$ dice que fue la difusión de la información la que socavó la paciencia artesanal y demorada que estaba en el origen del arte de narrar. En nuestro corpus, sin explicaciones ni moralejas, recopilando historias desconocidas, de hombres ignorados, de esa nación "abstracta" que es la Argentina para el autor ${ }^{6}$, los narradores llenan vacíos, dan voz a los que nunca la tuvieron en la cultura letrada, presentan tipos que nunca fueron descritos ni narrados, les dan un lugar en el mapa cultural latinoamericano. La narración cumple así los dos papeles: información y formación en cuanto transforma las percepciones y la imaginación al presentar nuevas bases y acepciones a las nociones antiguas. La Argentina es también, y por definición, ese mundo que Conti presenta. Como el Leskov de Benjamin, Conti también se consideraba un artesano y los vestigios de su experiencia están en toda su narrativa: desde los detalles que describen a sus amigos isleños, vagabundos, viajeros, hasta sus propios diarios de viajes, sus lecturas, sus amigos escritores, los artistas de circo.

Quiero decir que en sus textos Haroldo analiza una problemática pesada desde el punto de vista político, aquella que se refiere a las memorias, las formas de vida, las solidaridades, en fin, las identidades de nuestro pueblo. ..Se ubica en toda una vertiente [de la literatura de nuestro pueblo. ..Se ubica en toda una vertiente [de la literatura concreta, de la reflexión sobre las aspiraciones, las frustraciones, las broncas que vemos alrededor, frente a aquellas que parten de las ideas universales, de lo abstracto, de las teorías.

Es que Haroldo tenía una especial preocupación por un aspecto de nuestra historia social que es totalmente marginado, el de la historia del trabajo, las tecnologías, las invenciones. Esto, que pocas veces es analizado en su obra, como tampoco lo es en Quiroga, o en Arlt, o en Gudiño Kramer o en tantos otros, corresponde a una problemática muy profunda de nuestro país donde miles de inventores se frustraron, como el personaje Basilio Argimón, del cuento "Ad Astra", así como se frustró una Argentina industrial.'

$\mathrm{Si}$, como decimos con Jameson ${ }^{8}$, el lugar último de los subtextos es el de la contradicción social, observamos que justamente uno de los

\section{BENJAMIN, op. cit.}

6. "Todo esa Argentina que creo constatemente, porque para nosotras lo Argentina todavío es una abstrocción". Horoldo Conti en uno entrevisto a la revisto Attóntido, sin fecho. Citodo en RESTIVO, SANCHEL, 1986. p. 169.

7. FORD, opud RESTIVO, SÁNCHEZ 1986, p. 125-143. Ver el libro de SARLO, 1992.

8. JAMESON, 1991. p.96 desafíos de los procesos de producción de sentido en la ficción es trasponer un asunto de extrema riqueza y complejidad: los hombres inmersos en las relaciones de poder, debatiéndose en sus conflictos de clase, chocando sus vocaciones personales con las posibilidades mínimas, esas rendijas que a veces el poder deja abiertas. Los inventores, en este universo, aparecen como formantes de la sociedad a la que pertenecen el escritor y sus lectores; son imágenes creíbles que podemos analizar como esquemas simbólicos del imaginario social asociado al crecimiento del país, a su industrialización, a su realización como parte de un mundo al cual un país subdesarrollado como la Argentina aparentemente sólo puede integrar como observador marginal. La imaginación, en la forma de los "locos desvaríos" de algunos, aplaudidos o admirados, aunque también segregados por la sociedad que no se atreve ni a soñar tan alto, ni a abandonar las esperanzas de crecimiento, progreso y trabajo abundante para todos.

\section{Perspectivas y movimientos}

La primera perspectiva (las miradas) que podemos identificar en este corpus formado por las cuatro novelas de Haroldo Conti, es la individualista, en el marco de lo privado, que incluye el ser solo o el estar solo, la búsqueda de la salida individual. En este sentido, el deseo de salida se realiza en el registro de la interioridad, marcada como contradicción: la imposibilidad de encuentro entre deseo y solución. Conti emplea el recurso de seguir al protagonista desde su mundo interior dejando al lector en ese lugar desde el cual se despliega una mirada hacia la interioridad y otra hacia el mundo. Espacio textual ambiguo, es un juego de disloque entre esos dos polos.

En esa primera etapa, el punto de vista describirá los imaginarios de un individualismo feroz, reacio a encuentros interpersonales y al lenguaje comunicativo, y elaborará un espacio y un tiempo del lado de la naturaleza, con un tono elegíaco y una narración lineal lenta'; la ciudad sólo será vista desde las márgenes, en una mirada oblicua, ladina y finalmente, desde la delincuencia. Es Sudeste, la primera novela de Conti. Morello Frosch dice que Sudeste ejemplifica el concepto negativo de lo social en cuanto propone como un bien la soledad elegida y asumida por el protagonista que se presenta como única alternativa en cuanto libertad sujeta solamente a los vaivenes de la naturaleza.

9. MORELLO-FROSCH, 1983. p. 840
REVISTA DE ESTUDOS DE LITERATURA

Belo Horizonte, v. 3, p. 83 - 101 , out. 95 
Disponível em http://www.letras.ufmg.br/poslit

En una segunda fase, el punto de vista será el de la percepción de la alienación del hombre en la ciudad, mediante la gran figura metafórica del zoológico, del encierro, de la vida sin perspectiva en las grandes ciudades. Es Alrededor de la jaula. Será también la mirada esquizofrénica de En vida donde la acción dominante es la de la fuga, ya insinuada, imaginada y ensayada en la novela anterior. En esta tercera novela se concretiza el tema del viaje por el desierto. Son dos movimientos centrípetos, en espejo; la fuga con sus secuelas - secuestro, renuncia -, lleva a un punto cero a partir del cual el sujeto - el Boga, Milo, luego Oreste - se apropia de una identidad individual. Comienza entonces el nuevo movimiento, o la otra cara del primer movimiento, el viaje constructivo, en busca de la identidad social, del sujeto y del grupo, en la que finalmente la solución a los conflictos será buscada en el registro adecuado, es decir, en aquel en el que se producen las contradicciones y desde donde deberían partir las soluciones.

La tercera fase es la del germen y crecimiento del pensamiento utópico en que el ideologema es el de los encuentros y del desarrollo de las acciones colectivas: guerra y circo. El grupo, como sujeto que incluye las individualidades y las diferencias de la sociedad, elaborando los imaginarios que sustenten la nueva identidad en proceso. Es Mascaró, el cazador americano.

\section{Narradores}

En Sudeste existe un narrador extradiegético pero que demuestra sintonía con el mundo que narra y un conocimiento detallado del marco en el que sitúa los hechos. Al principio el narrador introduce ambientes y personajes, a la manera del cuaderno de bitácora de un navegante. Los ambientes, la naturaleza, como salidos de su conciencia: "se movía transportando consigo aquel mundo, dondequiera que fuese". (Sudeste, p.20) Hasta las estaciones, maneras de medir el tiempo, aparecen desde la conciencia del hombre: cómo lo afectan el verano y el invierno. "La infinidad de zanjas y canaletas que desagotaban sobre el cauce producían un murmullo adormecedor, más y más intenso en la noche, hasta penetrar en las venas". (Sudeste, p.34) "Uno mismo es invierno, uno mismo es verano" (Sudeste, p.39). El tiempo es medido en categorías extrañas al hombre como actante y a las que está sujeto. ${ }^{10}$
No sólo los hombres sino las cosas, principalmente los barcos, y también los espacios, tienen su historia y es el encuentro de las historias, la del hombre y las de la naturaleza, las del hombre y las del trabajo, las que se unen y se separan. El narrador se presenta como un observador directo de los acontecimientos y prevalece la impresión de que traslada a su novela una parcela de vida que le es entrañable por consistir en experiencias personales. Cuenta la historia con la seguridad de quien posee una amplia documentación. No es, pues, solamente, un narrador omnisciente. Es también un narrador-testigo, que permanece fuera de la acción pero se mantiene cercano a los hechos: de esta actitud narrativa provienen los marcadores de realismo:

. El uso del uno impersonal, que a veces es incluido en las experiencias del protagonista, el Boga, y otras veces aparece marcando distancia con el personaje destacando su presencia como otra voz. Como cuando dice: "El no pensó exactamente eso, sino que de pronto se sintió invadido por una extraña serenidad, una nueva placidez y una especie de risueño contento". (Sudeste, p.42). Antes había dicho que el Boga podría considerarse un vagabundo. De modo que este narrador (uno) cumple, en este caso, la función de interpretar: el Boga, por ejemplo, puede considerarse un vagabundo. Y aclara, el sentimiento de esto, no la idea, le provocaba una extraña alegría y una especie de rara seguridad. Digamos que la idea la tiene el narrador en función interpretante, el personaje va con el sentimiento.

Eduardo Romano", comparando Sudeste a Moby Dick, de Melville, y a $E l$ viejo $\gamma$ el mar, de Hemingway, habla de la "supuesta impersonalidad del que cuenta" que se cruza con la experiencia personal anterior y posterior a los hechos presentados, dando lugar a "uno de los desarrollos más inquietantes de la novela, precisamente la corporización progresiva del narrador". Romano persigue los signos lingüísticos que marcan esta experiencia y descubre que el narrador parece aceptar compartir con el protagonista, el Boga, sus vivencias del río y no su destino, ni su condición de vagabundo. Se trata de una construcción híbrida típica, con dos tonos y dos estilos. Según Bakhtine

construcción híbrida es el enunciado que, según índices gramaticales (sintácticos) y composicionales, pertenece a un único hablante, pero donde, en realidad, están confundidos dos enunciados, dos modos de hablar, dos estilos, dos "lenguajes", dos perspectivas semánticas y

11. ROMAN0, 1971. 
Las vivencias, como dice Romano, son compartidas, tanto lo que vive uno como lo que vive el Boga; pero el narrador puede abstraer ideas y hacer interpretaciones que abarcan también otro tipo de experiencias, que intelectualiza la praxis del pescador y universaliza sus sentimientos. Morello-Frosch dice que son seres narrados por una voz que se separa de ellos y que establece para sí esa indiscutida materialidad. Podemos observar que ese narrador quiere que el lector sepa de su saber referente al río, a la costa, a la pesca y a la visión del mundo referente a esas personas. Por eso, en ocasiones no se trata de interpretaciones sino de agregados informativos, como cuando el narrador especifica los nombres científicos de los peces y dice: "El había notado una leve diferencia entre los dorados. Unos tenían la trompa más alargada y otros, en cambio, la mandíbula inferior hacia arriba, como las tarariras. El primero es el Salminus maxillosus, y el segundo el Salminus brevidens. El ignoraba estos nombres, naturalmente, pero de todas maneras había advertido la diferencia y prefería..." (Sudeste, p. 63). El narrador sabe siempre más que el personaje, exhibe su saber y considera "natural" el hecho de que quien narra posea más sabiduría, esté más informado. Esta distancia entre el narrador y otra voz posee los elementos técnicos del autor-implícito y establece una jerarquía de visiones. Dal Farra dice que de este modo, la visión que lleva al lector a comprender el mundo que lee y a participar de él no es fundamentalmente la utilizada por el narrador. ${ }^{13}$ Sin duda, el punto de vista del narrador es el punto de referencia o la visión explícitamente conductora de la reelaboración del mundo por el lector, pero no la única ni la verdadera.

. La minuciosidad y el detallismo, sobre todo, en las descripciones del trabajo de los isleños y de su lucha por la sobrevivencia; el inventario del patrimonio material: pequeñas herramientas y restos de motores que se transforman de chatarra en objetos útiles, casi preciosos; las tareas típicas de lo cotidiano, del día a día: armar un refugio, calafatear un bote, cebar una línea. El narrador tiene sus raíces en el pueblo, principalmente en las camadas artesanales, dice Benjamin ${ }^{14}$. Así este narrador de Sudeste, metido de cabeza en las experiencias del río y del sufrimiento de los pescadores, en la soledad de los isleños; va tejiendo su discurso con el vocabulario que ofrecen el ripo de trabajo, los utensilios usados, los sistemas de comercialización y los medios comunes de sobrevivencia típicos del grupo. Toda una gama de palabras y de expresiones técnicas específicas confirman el envolvimiento del narrador con la narración.

. El uso de elementos valorativos denuncia al autor implícito, como cuando dice: "Este viento le recordó el río abierto y le trajo su nostalgia. No hay uno de estos tipos que resista ese olor del río" (Sudeste, p.65). Estos tipos excluyen al narrador que se coloca en la vereda de enfrente, aunque en otros pasajes comparta la vivencia del personaje. Lo mismo ocurre cuando se trata de sensibilidad ante el sufrimiento. Cuando el Boga observa impasible la agonía de un pato, el narrador dice: "Pero él tiraba un poco y no se le ocurría pensar en la clase de muerte que padecía el pato, allí debajo del agua ni cuánto tardaría en morir". (Sudeste, p. 66)

. El narrador se planta alejado de las relaciones de clase habitualmente mostradas, buscando estratos de la vida pobre y marginalizada de algunos actores sociales. Si el tema es diferente, también lo es el tratamiento literario. La clave de este tratamiento está en el juego entre lo que se muestra y lo que se sugiere, lo que se dice y lo que se calla. Existe una relación íntima entre la materialización del lenguaje y la de la experiencia narrada en esta novela. El imaginario del personaje delinea un lenguaje particular que le es parte integrante en cuanto se transforma en símbolo de un tipo de vida "en busca de" y en "resistencia a". El "cuadernito de recetas' del escritor realista le permite a Conti usar sus observaciones de la vida de los pescadores, recurrir a sus propias experiencias personales como pescador y transponer ideales propios de una clase diferente a la suya en esa simbología del pescador en busca del objeto sagrado y de otro tipo de vida, haciendo una religión de la que vive. El escritor se aleja de su propia y personal relación clasista para mostrar otra, aunque a partir de experiencias personales. Nos permite reflexionar sobre las funciones del escritor, los objetivos áltimos de los textos literarios. La obsesiva persecución de diversos objetos, el dorado, el pejerrey, el barco, por parte del personaje, ¿tiene como objetivo último simbolizar la difícil y traumatizante tarea del escritor que se desgarra en la búsqueda de la palabra, del estilo, del cómo figurar? ¿Es una manera de simbolizar la lucha del escritor comprometido con su tiempo, combativo e disconforme que quiere encontrar el lenguaje esencial de la literatura para acompañar su lucha, sin por eso traicionar a la literatura y transformándola en un medio de publicidad y propaganda? ¿Ese pescador que erra por el río hasta la muerte puede ser tomado como una alegoría del proceso de creación, del proceso de búsqueda del método de trabajo? Esa tematización, como sabemos, es 
Disponível em http://www.letras.ufmg.br/poslit

esencial para la sensibilidad moderna que siente un placer intelectual especial al seguir los procesos de creación, más que en la complacencia ante el objeto ya realizado.

. El uso de construcciones que pasan por encima de los personajes y establecen la conexión autor implícito-lector ideal. En Mascaró, el cazador americano, por ejemplo, los relatos sobre la historia, generalmente los referidos a las fundaciones de ciudades y su posterior desenvolvimiento, personajes intervinientes, etc., aparecen como este otro tipo de agregados informativos que entran en la narración como una cuña. Son microrrelatos que actúan a modo de agregados en la narrativa siguiendo un modelo de estructuración que relaciona directamente narrador y lector. En la página 79, por ejemplo, referido a Palmares, leemos un agregado que ocupa desde la página 73 a la 79 , contando en un estilo que parodia el discurso históricoescolar asuntos relacionados con la historia del lugar; sin embargo, los personajes permanecen ignorantes de toda esa información que le es transmitida al lector:

Palmares..., me pregunto cómo nació y creció y vino a ser lo que es - discurre el Príncipe mientras observa el faro que resbala sobre los techos a medida que el carro trepa por una calle de adoquines.

Más o menos la misma historia de siempre - dice el Nuño. Unos tipos que se extraviaron o los tomó una tormenta, y después todo ese trajín del tiempo.

El narrador de estas novelas no se substrae a la experiencia de la muerte. Como dice Benjamin ${ }^{15}$, con la desaparición de la narrativa clásica y hasta el siglo XIX, se excluye la muerte del mundo de los vivos en la literatura postmoderna. Lo que era el espectáculo que permitía que el saber y la sabiduría del hombre y su existencia vivida asumieran forma transmisible, se volviera ejemplar. En Mascaró, el cazador americano, el narrador llega a introducirse en la sensibilidad de un personaje secundario, el hombre del Aldebarrán... sólo para narrar este episodio desde el sentir de la víctima, un tipo de "mente dramatizada", deslizando el foco narrativo. La muerte del Boga, que cierra la novela, es narrada como la del viejo, que ocurre al comienzo. El Boga muere lúcido y esa muerte llega al lector desde la autoconciencia del personaje, es por eso que queda inconclusa. Sabemos lo que el personaje piensa y siente casi hasta los últimos momentos. Ya no podía ver el poco de luz que había observado a lo lejos, un rato antes pero seguía frente a la noche con sus grandes ojos de pez

15. BENJAMIN, op. cit.
Disponível em http://www.letras.ufmg.br/poslit

moribundo desmesuradamente abiertos (Mascaró, el cazador americano, p. 160 ). Siendo que los ojos de pez moribundos es un motivo que atraviesa toda el texto: es así como el narrador ve al Boga, con la muerte incrustada en su imagen.

Hay secuencias en las que el narrador se desplaza libremente, como en la inicial, en el trazado de un mapa cognitivo de la zona del río y de algunos personajes. El "punto de vista" en esta novela es de tipo fílmico: tomadas, giro panorámicos y yuxtaposiciones que juegan con la competencia receptiva del lector que se ve obligado a reunir imágenes, buscar la coherencia, rellenar los vacíos con significación y totalizar el significado. Son las convenciones que rigen la lectura de la poesía también. El lenguaje a que llamamos "fílmico" tiene muchas de las características del lenguaje poético: juega con la deixis y la distancia, se exhibe en la riqueza metafórica, apela a la simbología y alegoriza los objetos. El lector contiano sabe que debe buscar en todo eso siempre los dos niveles: el concreto de la lucha del hombre humilde y desprotegido y el espiritual del hombre también humilde y más desprotegido aun en busca de su identidad. De una entrevista, tomamos esta declaración de Conti:

Alrededor de 1950 frecuenté el grupo Gente de Cine que dirigía Roland y del que formaban parte Pipo Mancera, David Kohon, Burone. Obtuve dos becas de Gente de Cine en 1952 y 1953 y trabajé como asistente de dirección en $L a$ bestia debe morir. En todos mis libros he visto a los personajes como parte de una película; yo necesito encarnarlos, pensarlos como seres vivos, darles cara y cuerpo para poder escribir sus historias. No sé si se nota demasiado, pero Sudeste fue inicialmente un libro cinematográfico. El montaje de En vida también tiene el tratamiento y el montaje de una película. Ahora estoy pensando casi exclusivamente en un argumento que pensamos filmar con Nicolás Sarquis (La muerte de Sebastián Arache y su pobre entierro), que transcurre en La Rioja, en el Valle de la Luna, y narra una revolución de comuneros, porque aunque parezca increíble todavía hay comuneros en la Argentina.

¿Si mi preocupación se centra en la estructura o en el lenguaje? Creo que en un determinado clima, y la imagen (sensu cinematográfico) en función de ese clima. Esto en términos generales. Me gusta la idea de Pavese de que la cosa consiste en crear climas y atmósferas. El resto se da a través de eso. En cuando al lenguaje y la estructura, no veo cómo puedo separarlos. Existe hoy una literatura que ha hecho del lenguaje su exclusivo protagonista. ¿Qué es eso? Un cierto ruido, el oficio de la vacuidad, cominerías, al pedismo, nada.

Las escenas son yuxtapuestas, editadas en el proceso de composición, como dispuestas para ser filmadas, con la expresión de algún 
Disponível em http://www.letras.ufmg.br/poslit

punto de observación que coincida con el del lector/espectador. Para eso usa a menudo verbos de observación: ver, contemplar, advertir, que normalmente van acompañadas por expresiones valorativas. Las cuadros son mostradas o como escenas o en visiones panorámicas. Las acciones oscilan entre ser presentadas con minuciosidad, con la preocupación del efecto a ser causado, como en este fragmento:

Por ahora está en medio del río. Como en medio del mar. Cuando el barco cabecea se siente un breve chasquido bajo la roda. El viento silba en las jarcias sin darse un respiro, como si eso lo divirtiera. Las velas se mantienen combadas y a veces se sacuden. Uno siente en la propia sangre aquella pareja y constante presión. Aquí y allá, vacilando en la lejanía, aparecen puntos imprecisos que uno ubica ansiosamente sobre las cartas. Es increíble el efecto que produce una boya o una baliza avizorada a lo lejos. Toda la ansiedad se concentra sobre ese punto impreciso, al que se le asigna un significado tremendo. Pero si uno lo observa con demasiado detenimiento, desaparece. Está oscureciendo. Los puntos comienzan a guiñar. Hay algo cálido y hasta tierno en cada resplandor. El barco navega ahora en la noche. El río es oscuro y torvo. Enfila hacia una boya con destellos blancos. La silueta negra crece y se bambolea como un fantasma. Cuando pasa al lado, se nota el siseo del agua resbalando contra sus bordes. Estas enormes boyas sobrecogen un poco. Su luz es amable a la distancia, pero una vez cerca, erguidas como un peñasco, tienen un aspecto sombrío. (Sudeste, p. 40)

$\mathrm{O}$, como decíamos antes, presentados a la manera indirecta de la poesía. Lo que busca el narrador es crear el clima, la atmósfera en la que la acción se desenvuelve. No es sólo el Boga quien lo siente, es el narrador quien poetiza el ambiente, se deja llevar por un sentir de ensoñación. El río lo envuelve como al personaje, pero es el narrador quien puede verbalizar y figurar, no pretende que eso se transforme en lenguaje del personaje. La conciencia que reflexiona recibe los estímulos provenientes del cuadro mostrado. El secreto estriba en que los hombres como el Boga son hombres del río, en cuanto que el narrador es un amante de la naturaleza y de esos hombres que en ella viven o sobreviven, un investigador, un poeta. Dice:

Sus hombres, los hombres de este río, este hombre que ahora observa las aguas con sus ojos de pez moribundo suspendidos sobre ellas como dos espejuelos suspendidos del aires, son en todo semejantes a él. Por eso todavía sobreviven. Por eso parecen tan viejos y lejanos y solitarios. No aman al río exactamente, sino que no pueden vivir sin él. Son tan lentos y constantes como el río. Parecen entender que ellos forman parte de un todo inexorable que marcha animado por cierta fatalidad.
Disponível em http://www.letras.ufmg.br/poslit

Y no se rebelan por nada. Cuando el río destruye sus chozas y sus embarcaciones y hasta a ellos mismos. Por eso también parecen malos. (Sudeste, p. 47)

En Alrededor de la jaula, el narrador asume el punto de vista de la interioridad de Milo pero deja entrever entre los dobleces de la narración, al autor-implícito que en su no-objetividad, muestra sus propias inclinaciones, sus gustos, sus opiniones. Simultáneamente, van siendo mostradas las de Milo que no siempre coinciden con las del autor-implícito, que demuestra una experiencia más profunda, es un conocedor más experimentado, se encuentra en la frontera de la diegesis. Cuando el narrador asume el punto de vista de Milo, lo hace por medio de una operación restrictiva: debe reducir el ángulo de visión y experiencias: "Para Milo el mundo conocido estaba entre el río y aquellos edificios. Sólo que el río parecía querer decirle algo y aquellos edificios no le decían absolutamente nada." (Alrededor de la jaula, p.14)

En otros momentos, el narrador asume el punto de vista de Silvestre (Alrededor de la jaula, p. 14 y 15). Las dos perspectivas se alternan y es lo que produce la densidad de la narrativa: "No le sucedía como a Silvestre, que se movía más bien ante el recuerdo de las cosas, sino que las veía tal cual eran y veía justamente el lado que tenía adelante". (Alrededor de la jaula, p.19)

Esa alternancia deja ver la espesura de la narración, entre la mirada ingenua del adolescente que está creciendo, la sociedad que se le viene encima en forma de responsabilidades, la vida dolorosa y la mirada "de despedida" del más viejo que, hacia el fin de su vida, observa las cosas con desencanto y con los ojos de quien va a partir. Esa oscilación entre los dos puntos de vista que se complementan se produce incluso en la percepción del clima y del paisaje, del espacio. El narrador registra las dos: "Todo aquello le entraba a Milo por los ojos y él se sentía flotar también, liviano pero seguro, sobre la gente. Silvestre, en cambio, era una sombra sudorosa que arrastraba a su otra sombra...Un resplandor inmóvil en los ojos, para los que ya no había ni verano ni invierno, como no fuese en el recuerdo, en los mechones blancos que asomaban por debajo del sombrero y en los pliegues mansos de sus labios". (Alrededor de la jaula, p. 29)

El florecer de una mirada joven que observa con avidez y pasión y el suave declinar de quien está muriendo. La vida dando una explicación a la muerte, todo se renueva y recomienza. La mirada, las experiencias, la vida de Silvestre, no se pierden; se transforman a través de lo que el amor del viejo y la convivencia despertaron en el joven. Las miradas se confunden 
a veces y enriquecen la visión de uno y de otro. Como cuando el narrador dice, de Silvestre, "pero de todas maneras a través del muchacho había terminado por ver bajo otra luz aquella especie de enorme corral lleno de animales viejos y achacosos [se refiere al jardín zoológico]". (Alrededor de la jaula, p.29)

Para el viejo, el pasado se mezcla con el presente y lo explica, en cambio para Milo, el pasado todavía no existe casi, no tiene relevancia frente a la turgencia del presente; la mezcla de lo viejo con lo nuevo le resulta a veces misteriosa. Como cuando Silvestre mezcla los recuerdos de un jardín zoológico que "tal vez ni siquiera había existido", según piensa Milo, que carece de nociones que podrían ayudarlo a pensar a partir de la memoria, hacia atrás en el tiempo. El narrador asume la figura de un árbitro, juez a veces cuando toma partido, pero generalmente se sitúa comparando una y otra visión. La postura del autor-implícito se materializa cuando dice, por ejemplo, "se sabe que la distancia cobra cierta desmesura". O cuando dice que Silvestre hablaba de "un sospechoso y complicado lagarto de Nueva Guinea", etc. El uso del adjetivo sospechoso hace que el narrador asuma el elemento de incredulidad que le adjudica a Milo. Y luego agrega que Milo no había conocido otro jardín en su vida, de manera que su visión del jardín era tal cual era, no podía establecer comparaciones. A Milo se suma Tita, la otra adolescente entre los personajes, de quienes el narrador puede decir que "no había rencor ni memoria en sus cabezas jóvenes". Otras veces el narrador deja lugar al autor implícito que interviene para revelar sus propias ideas sobre el asunto que está contando. Como cuando dice: "En general, observándolos con atención, todos estos animales, por grotescos que sean, tienen algún parentesco con la gente... La gente no ve nada de eso. Es decir, ve tan sólo aquello que los hace distintos y los aparta”. (Alrededor de la jaula, p.30)

Más adelante aclara que Silvestre, cuando sacaba la cabeza de su jardín, veía las cosas como Milo, de manera que el hombre que está despidiéndose de la vida material, ve las cosas como el joven. También la mangosta es motivo para que el autor-implícito no solamente manifieste sus opiniones al respecto sino para que en algún momento asuma los sentimientos del animal. "La mangosta parecía más resignada con su suerte" (Alrededor de la jaula, p. 35) para luego aclarar que "eso pensaba Silvestre" También Tita será enfocada por el narrador cuando finalmente se interioriza del punto de vista de los otros dos personajes y puede compartirlos; adquiere el código ideológico común que permite la comunicación.

Todo esto y los barrotes que le impedían moverse a gusto hizo
Disponível em http://www.letras.ufmg.br/poslit

que la muchacha viera el mismo lado de las cosas. Aquello no era otra cosa que un vulgar calabozo y el conjunto una cárcel bien disimulada en ese viejo y simpático jardín. Por eso tal vez cuando volvieron a la jaula de los pájaros, antes de salir, vio por lo menos un poco de toda esa tristeza, la brevedad y pesadez del vuelo, el simulacro de montaña, las rejas cubiertas de alambre, la vejez de los árboles, el cerco empinado de los grandes edificios y, recién mucho más allá, un pedazo de cielo. (Alrededor de la jaula, p.42)

Luego de la enfermedad y muerte de Silvestre asistimos al dolor de Milo. Ahora es el narrador solamente quien abarca en su experiencia a la del joven que "veía las cosas a su medida". (Alrededor de la jaula, p.132)

Así como en Sudeste, el narrador juega con el recurso de la anticipación. Antes de contar un episodio lo adelanta sumariamente. En página 32 dice: "Milo recordaría siempre esa primera vez que lo vieron, en octubre, como queda dicho". Adelanta acciones que vendrán para, de ese modo, marcar la importancia de lo que va a narrar que, en este caso, será el encuentro de los personajes con la mangosta. El narrador controla la historia y por lo tanto no puede estar obligado al tiempo en el que transcurre la historia; por el contrario debe enfocar los dos lados del tiempo, flexibilizando su visión de modo de poder transitar pasado, presente, futuro. Gana así en movilidad retrospectiva y anticipativa a partir de la cual puede seleccionar los signos que usará en la novela y establecer adecuadamente los puntos tensionales. Sólo así puede ser guía del lector y orientarlo en el camino narrativo.

En En Vida, el narrador adopta también ciertas posturas de guionista de cine; el lector es colocado frente a las acciones y los personajes como el espectador ante una pantalla. Lo que se leen son verbos en presente que dan la clara impresión de que las cosas están sucediendo tanto para el lector como para los personajes y para el narrador. Éste se comporta como un acotador que organiza las escenas con todos los detalles necesarios para filmarlas, que pretende que esos pormenores compongan los sintagmas que estructuran la película.

Las situaciones narradas sugieren el efecto de lo real, para lo cual confluye la experiencia del autor como periodista investigativo. Situaciones "reales" estilizadas en la búsqueda evidente de un lenguaje verdadero más que verosímil, que llega a rechazar la verosimilitud porque justamente lo aparta de lo real. A veces lo más fantástico o imaginativo permite una acercamiento más profundo a un lenguaje verdadero. El estilo se convierte en una manera de vivir, el ser se conjuga con el hacer y el quehacer literario 
es el quehacer vital, un punto de encuentro de esas actividades, el espacio del ser. El lenguaje contiene así el yo, se transforma en el intermediario rígido y firme entre la conciencia y el objeto o acontecimiento y presenta la lucha del encuentro en económica y tensa autenticidad. El hombre que es Oreste vive con un pie en un mundo y el otro en otro, ambos mundos irreconciliables. En el de la ciudad, la respetabilidad, el trabajo, la familia, visto con el desengaño y el desespero de quien se siente preso, ahogado, fracturado en su conciencia. El otro, en el que la naturaleza es un marco y los hombres son seres que transitan por la vida entre el alcohol y la resistencia a la rutina, deambulando borrachos, buscando emociones y un sentido a la vida, destituida de la moral tradicional, la religión o cualquier otro componente del estilo de vida habitual. Esos hombres parecen buscar la autenticidad, derrumbar los esquemas falsos y es en esa base que se asienta la amistad que los une y la relación de Oreste con Margarita.

El resto de la experiencia gira en el vacío, la ciudad y todo lo que ella representa es la nada donde el hombre, Oreste, no encuentra asideros, se siente desplazado, fuera de lugar. Fuera de allí, en la costa, en medio a una existencia caótica y desordenada, existe para Oreste una pequeña luz a la distancia desde donde poder imaginar un futuro.

En ese lenguaje de economía poética, el narrador por momentos describe sólo acciones y por momentos entra en la cabeza de los personajes y piensa con ellos, recuerda escenas del pasado y se inmiscuye por medio de deícticos y de lenguaje subjetivo. En otros momentos profetiza, adelanta lo que vendrá."Está amaneciendo. Ahora no significa nada pero Oreste recordará mil veces este momento..." (En Vida, p23)

En Mascaró, el cazador americano, el narrador se responsabiliza tanto por el modo descriptivo (constata, registra) como por el narrativo. Es también el encargado de otra función, la de poetizar, haciendo uso de dos tonos: el fundacional, de nombrar creando [Heidegger] y el profético, el poeta es un vate: vaticina. En el caso de Conti su uso particular del sistema poético le permitió trabajar con asociaciones arraigadas en la memoria colectiva y el imaginario social. El narrador va mostrando el progresivo comprometimiento social de Oreste y de los otros personajes. Tratando de la guerrilla sudamericana, argentina, en el nivel de lo no-dicho (lo legible pero no escribible), va mostrando al héroe pasando de hombre solitario y bohemio, perdido en su circunstancia, a héroe rodeado de un grupo que transita hacia la clandestinidad de la lucha armada: casi todos los actores de la troupe del circo y los tripulantes del barco EL MAÑANA, se transforman en guerrilleros. Oreste comienza en transición, pero va adquiriendo convicciones respecto a la necesidad de la lucha y del sacrificio, en una especie de unión con la gente y el espacio: el mar es un marco y a la vez un símbolo, de allá vino y allá va, a cumplir su destino. Aprendió a ser solidario, reconoció el camino. Del existencialismo de las otras novelas se llega a este narrador que acompaña a los personajes basado en un humanismo socialista donde cabe todo tipo de acción y todo tipo de personaje, todos pueden ser héroes y agentes activos de la causa.

También el lenguaje cambia, como cambia la ideología. Aquel ascetismo económico da lugar a lo que llamamos realismo poético, donde la poesía tiene lugar, desbordando el escueto y trabajado lenguaje de las novelas anteriores, sin pudor. La significación indirecta, los usos poéticos, forman parte de este nuevo hacer, uno de cuyos objetivos es el de estetizar lo popular, ennoblecerlo. El nuevo mundo que se está creando precisa una nueva palabra que no le tema a la poesía y al desborde y que busque rescatar la información sojuzgada o reprimida enfocando las prácticas significativas que sostienen la forma en la cual esa información se presenta. Esta se constituye en una vía para transgredir los límites disciplinarios y las estructuras jerárquicas dentro de las cuales el conocimiento y la experiencia se organizan; lo nuevo es la posibilidad de cooperación, de creación colectiva. Este nuevo escenario es político y artístico y la idea de la celebración de la vida va tomando cuerpo.

La vida es célebre, de cualquier tamaño, o no sirve para un carajo. [Dice Mascaró] (Mascaró, el cazador americano, p. 54).

Mascaró declaró que apreciaba esos intermedios, que estaba de acuerdo en que la vida del hombre sobre la tierra es una milicia pero que ésta, a su vez, era un arte que se ejercitaba, que las buenas guerras se adornan como una representación, son casi un festejo, que él, Mascaró, por otra parte, era en lo personal hombre de concretos, como el capitán Alfonso Domínguez, que se expedía de oficio, no con simulacros, sin ánimo de ofensa en esto ni apreciar ventajas entre una forma u otra de vida, que uno nace volatín y otro capitán y cada cual tiene su misión sobre esta tierra. (Mascaró, el cazador americano, p. 57)

El arte es un arrebato. Fue una pregunta al pedo, o mejor dicho para que te respondieras tú mismo. Sé bien lo que es eso. Puedes hacerlo con una figurita de nada, con una rasposa historia, no sólo son sencillos materiales sino hasta con los más vulgares. Todo depende del aliento, la forma y la disposición... (Mascaró, el cazador americano, p. 63)

El trabajo del narrador en esta novela es el de organizar el lenguaje que se propone como nuevo, aunando retórica y patrimonio poético y 

los dichos populares y el lenguaje pomposo de la retórica popular. El juego del narrador es la asimilación de la riqueza de la oralidad y de los saberes populares, la riqueza de la retórica lúdica, la retórica cursi y el lenguaje cotidiano, el placer del chiste que criba la superficie acartonada del parlamento formal con gran soltura. Para eso realiza un trabajo de examen de los códigos - culinario, gustativo, olfativos, astronómico, acústico, zoológico, sociológico, cosmológico - que van apareciendo en su camino. La búsqueda de los lenguajes específicos por parte de los personajes es mimetizada por el narrador, que toma los elementos de todos y cualquier texto que se le ofrece y los inscribe en el texto mayor de la novela como resultado de una organización de diferentes y diversificados sectores de experiencia. El texto contiano, en especial su narrador privilegiado, se ubica en la función obligatoria y preferencial de enunciador de quienes no tienen lugar en el esquema oficial de enunciados; pone la lengua en funcionamiento como un locutor cuyo acto asume procedimientos y caracteres formales dictados por sus nuevas experiencias de campo: gracias a su fuerza enunciadora, como conocedor profundo de los códigos y convenciones de la literatura como institución, la palabra de los que no tienen el predominio, puede fluir con fidelidad y potencia. Su acto individual de utilización, su acto enunciativo, es en realidad una enunciación colectiva y su referencia al mundo es la de marcar una presencia y distribuir el poder del lenguaje. El poder de la lengua significa en este texto la lucha contra el canon lingüístico en sus distintos niveles, colocando como blanco el autoritarismo instalado en el lenguaje. Contra la homogeneidad inculcada a la fuerza, la regularidad exigida, la igualdad pretendida, lo que se celebra y se consagra es lo diferente, lo desconocido. El narrador de Mascaró, el cazador americano, anda a la búsqueda de una expresión propia y la encuentra junto con la toma de conciencia de sus personajes. Se trata de ejercer el narrar colectivo al que todos tienen derecho; al rescatar este saber se rescata el placer de la cultura que puede ser festiva y ritual, que puede ser una vía de conocimiento individual y grupal, una forma de conocer a los otros, al mundo y a sí mismo.

REFERÊMCIAS BIBLIOGRÁFICAS

BENJAMIN, Walter. Obros escolhidas. São Paulo: Brosiliense, 1987. V. 1: Magio e técnica, arte e política - ensoios sobre literotura

contr, Horoldo. Sudérioste. Buenas Aires: Compoñia Fobril Editora, 1962

Alrededor de lo joula. Xolopa, Mexico, 1966. Buenos Aires: Editoriol Sudamericona, 1967

En vida. Barcelono: Barral, 1971

Moscoro, el cazador omericano. Buenos Aires: Nuevo Imogen, 1984

FARRA, Morio Lúcia Dol. o norrodor ensimesmado, toco norrotivo em Vergílio Ferreiro. Söo Paula: Ática, 1978.

JAMESON, Fredric. Ensayos sobre el posmodernismo. Buenos Aires: Imogo Mundi, 1991.

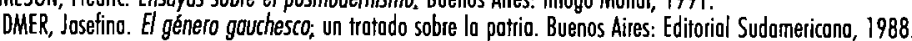
MORELLO-FROSCH, Morto. "Áctualizoción de los signos en la ficción de Horoldo Conti". Revisto lberoamericona, ñ 125, octubrediciembre 1983.

RESTIVO, Néstor, SAANCHEZ, Comilo. Haroldo Conti, con vida. Buenos Aires: Editoriol Nueva Imagen, 1986.

ROMANO, Eduordo. NARRADORES ARGENTWOS DE HOY. I. Buenos Aires: Kopelusz; G.O.L.U., 1971

. 1989

SARLO, Beatriz. La imoginación técnica, sueños modernos de la cultura argentino. Buenos Aires: Ediciones Nueva Visión, 1992 